\title{
The dynamics of traffic congestion: a specific look into Malaysian scenario and the plausible solutions to eradicate it using machine learning
}

M. Ali, T. K. Sheng, K. M. Yusof, M. R. Suhaili, N. E. Ghazali, S. Ali

Advanced Telecommunication Technology (ATT) Research Group, School of Electrical Engineering, Faculty of Engineering, UTM, Malaysia

\begin{tabular}{l} 
Article Info \\
\hline Article history: \\
Received Sep 8, 2018 \\
Revised Jan 20, 2019 \\
Accepted Mar 15, 2019 \\
\hline
\end{tabular}

\section{Keywords:}

Big data analytics Machine learning Transport framework Uncontrolled urbanization

\begin{abstract}
Transportation has been considered as the backbone of the economy for the past many years. Unfortunately, since few years due to the uncontrolled urbanization and inadequate planning, countries are facing problem of congestion. The congestion is hindering the economic growth and also causing environmental issues. This has caused serious concerns among the major economies of the world, especially in Asia-Pacific region. Many countries are playing an active role in eradicating this problem and some have been quite successful so far. Malaysia, being a major ASEAN economy is also tackling with this huge problem. The authorities are committed to solve the issue. In this regard, solving the issue leveraging the use of big data analytics has become crucial. The authorities can form a complete robust framework based on big data analytics and decision making process to solve the issue effectively. The work focuses and observes the traffic data samples and analyzes the accuracy of machine learning algorithms, which helps in decision making. Yet, here is a lot to be done if the government needs to solve the problem effectively. Supposedly, a comprehensive big data transport framework leveraging machine learning, is one way to solve the issue.
\end{abstract}

Copyright $\odot 2019$ Institute of Advanced Engineering and Science. All rights reserved.

\section{Corresponding Author:}

M. Ali,

Advanced Telecommunication Technology (ATT) Research Group,

School of Electrical Engineering,

Faculty of Engineering,

UTM, Malaysia.

\section{TRANSPORT CONGESTION: A PROBLEM THAT NEEDS TO BE SOLVED}

Over the past few decades transportation has significantly changed the lifestyle of the people. Transportation has given the power to the countries to be able to think differently. Visible effects can be seen as a result of an efficient transportation throughout the world, ranging from the goods transport to the everyday commuting. The $20^{\text {th }}$ century has experienced a rapid rise of transport facilities as a result of technological maturity. But, in the $21^{\text {st }}$ century, things have grown up exponentially and to an extent that seems to be going out of human's control. Although, with the advent of faster modes of transportation and the easy ownership of cars, life is certainly made easy, but this is coming with a great cost to the environment. With the sudden rise of transport vehicles, it was quite evident that carbon emission is going alarmingly high. The environment threat from the transportation is only a tip of an iceberg. The real problem that the governments of almost all the countries face is the vehicular congestion. The problem of congestion has proven to be a bottleneck for both the developed and the under-developed regions around the world. Many parts of the world seem to have surrendered over this not so addressed issue. On the contrary, many governments are proactive and are paying their fair share in mitigating this menace in order to induce the way to a prosperous future [1]. 
Different parts of the world are quite determined to tackle the problem. Congestion has affected the world major economies in various aspects. The economists have experienced a significant effect on the national GDP due to the high congestion. Several problems, that affect the overall life of the citizens, have arisen as congestion advances in major places. The impacts of congestion have been felt severely by the major countries of the world. Several policies are to be blamed for this outcome. Uncontrolled motorization, lack of traffic sense and lack of urban transportation planning are some of the factors to be blamed for. As far as the major economies are concerned, the congestion has been a serious concerned for them. An agency, INRIX mentioned that the total annual expense accounting for congestion in USA, France, UK and Germany will be \$293 billion by 2030 [2].

The most damage will be seen in UK which will be the $66 \%$ of the total cost. This is mainly due to the rapid increase in urbanization. American cities such as New York also face the problem of congestion. Several European cities follow the same suit. Cities such as Paris, London and Rome have been affected significantly due to this serious issue [3]. The problem is not only confined to that region. For the past decade Asia has experienced exponential economic growth in every aspect. Many Asian cities have been thronged by people from the countryside, which have come to find better future there. This has led to an uncontrolled migration leading to the problem of congestion. These countries are very concerned regarding the situation as it can have a negative impact on their economy. If the situation prevails, it can result as a gridlock for them affecting their economy significantly. The congestion situation in various major cities of China has been in worse shape since the country has experienced rapid economic growth. Beijing has faced the problem of air pollution for past few years. The government has been seriously concerned and working proactively to mitigate this issue. Similarly the situation is a bit similar for countries such as Japan and South Korea. Seoul has imposed a fee for using a certain road, to rectify the problem faced because of congestion [4].

The pricing method helped in reducing the congestion for the major corridor. Similarly Singapore also uses the same kind of approach. Singapore government has been working very actively to tackle the problem faced by the congestion. As Singapore is running out of space to make new expressways, the government has come out with a strategy to charge a fee for using certain roads for a given period of time. At off-peak there is no charge taken from the motorists [5].

In this whole scenario, being a major ASEAN economy, Malaysia is also paying its role to solve the problems that congestion induces. Malaysian government has been targeting to reduce the carbon emission by $40 \%$ by 2020 [6]. Malaysia is second largest per capita greenhouse gas emitter among the group of ASEAN countries. Although, Malaysia shares only $0.3 \%$ of global GHG emission the major concern lies in the ever increasing trend of GHG emission. Most of this owes to congestion scenario. During the emergency situation, the behavior of traffic always deviates from the norm and it tends to change drastically in other situation. This behavior results in the disruption of the traffic flow. Thus, creates complications for the relevant team to carry out their task in shorter time. The traffic congestion has caused serious concern among the authorities in Malaysia. The Malaysian government has taken steps to reduce the intensity of the problem. Different ways, in which the problem of congestion can be addressed, will be discussed later in this paper. The Malaysian congestion scenario is the focal issue in this work. In this regard, different initiatives will be mentioned, which are taken by the government to tackle this problem. The role of big data analytics will also be brought into limelight. Big data analytics can be proven very helpful in eradicating the problem of congestion in Malaysia. Various exampes of cities and the respective regions have been mentioned to get the clearer and deeper insight of the related issue in the coming section.

\section{CAUSES OF CONGESTION IN DIFFERENT REGIONS}

Various problems are to be blamed for traffic congestion throughout the world. Around the world it has been seen that several places have more or less similar magnitude of problem. Ranging from the developed cities to the cities of emerging economy, the issue is similar. We can get an estimate of the problem by looking into it on regional basis. Tables and Figures are presented center, as shown below and cited in the manuscript.

\subsection{European Cities}

European cities were the first ones to experience the rise of industrial revolution and the modern age. Numerous technologies were implemented in the 18th and 19th century in some of the major European cities. Although motor vehicles were considered as a late inclusion but they were used in the 20th century in huge amount. The last decades of the 20th century has seen something exceptional as the economy sprouted rapidly, with every citizen having a power to buy more than one vehicle. By then the car ownership has been skyrocketed. Cities such as Paris and London have seen the worst outfall of it. The commuting through the private vehicle has become increasingly difficult. Although the related authorities are vehemently working to cope up with the problem, but the issue does not seem to be resolved. One of the factor as mentioned by the 
researcher is the worst town planning. The uncontrolled urbanization is also one of the major causes [7]. On the contrary there are cities in the same continent which do not face these sorts of problems. The authorities, for the past two decades have been trying to motivate the citizens to use the public transport so as to reduce the impact of congestion. Many countries are providing the best transport facilities in the world, to their citizens so that they the use of the private vehicles for their daily commute, becomes pointless. But there is still that needs to be done. The congestion scenario has proven a bottleneck for the authorities and has resisted economic growth. Besides this it also has adverse effects on social behavior.

\subsection{The Americas}

The American continent (both north and south) have experienced detrimental congestion condition for the past few decades. In North America, with the exception of Canada, the situation is much worse than Europe. Several U.S cities become gridlock due to the congestion on the expressways. The situation in Los Angeles and San Francisco has been known to prevail for the three decades. Although there are steps been taken to eradicate the problem but still the ramifications caused by the congestion scenario are clearly visible. For the peak hours, it takes thrice the time to travel by car than the normal time taken. Traffic jams are the usual scene at the Brooklyn Bridge. The entire Manhattan is to be known by this problem since eighties. Same is the situation for other cities such as Detroit. Recapitulating all the facts, it is quite evident that the severity of the traffic congestion can cause concerns even for the economic power houses.

South American countries on the other hand are called the emerging economies. Where Brazil leads the way and other countries are following the trails. Brazilian cities are an obvious example of the uncontrolled urbanization of the cities. If we see the population map of Brazil, we can clearly see the disparity of the number of people living in cities than on the rest of the country. Cities such as, Sao Paulo, Brasilia and Rio de Janeiro are facing one of the greatest magnitude of congestion problems. Same is the case with Mexico, which is an emerging economy and is performing quite good based on the standards. But due to the chronic problems of town planning and other social issues the city has shaped up quite badly. There are other problems besides congestion but congestion alone is contributing much to pollution problems. The government of the emerging economies should address these problems; otherwise their economic prosperity will become futile at one point.

\subsection{South Asia and the Asia Pacific}

The Asian continent has been experiencing incredible changes in the 21 st century. Asian countries are on a brink to induce a remarkable change in the economic scenario of the world [8]. Countries of Asia Pacific regions such as, China, Japan, South Korea, Singapore, Malaysia and Indonesia are performing quite well for the last decade. The region has witnessed steep and positive growth rates with an increase influx of foreign investments. Similarly other countries of the regions such as, Vietnam, Philippines and Thailand are following the same trait. The countries of South Asia such as India, Pakistan and Bangladesh are also experiencing economic growth but this region faces a huge problem of exponentially increasing population which is surmounting the country's available resources [9]. The countries are eyeing for opportunities to create new resources in order to deal with increasing population. But the efforts are proving to be futile. Similarly lack of adequate transport infrastructure is also creating further problems. Due to the recent economic growth, more people tend to buy private vehicles and in many cases, more than one. This all results to severe traffic congestion, which has caused serious concerns among the experts and the authorities. It is quite clear that the economic growth comes with a huge cost. Recently Delhi, a huge mega city has experienced smog conditions in winter all because of the traffic congestion and the worst town planning. At a certain time, breathing in Delhi's air was like smoking 10 cigarettes daily. The government also tried odd and even number formula, but all went in vain as there was little effect on the congestion and the pollution [10]. Besides India, Karachi a mega-city in Pakistan also faces the problem of congestion [11]. Several signal free corridor were built in the last decade but due to the increase in population and the vehicles manifolds, have left the authorities baffled. They now have to devise a new and long lasting method to deal with such type of issues.

China has proven to be a major economic player in the world. The capital of China, Beijing has suffered from the problem of pollution. Congestion was one of the causes of that pollution beside the use of coal. But China has done remarkably well and in the winters, Beijing has experienced clear skies for most of the time [12]. China is doing much in this regard. A major Chinese company has deployed its traffic management system called "CityBrain" in Hangzhou, China. The system has effectively reduced the congestion on the city since it was deployed [13]. Similar efforts have been planned for Kuala Lumpur where the Malaysian government signed an agreement with Alibaba cloud, to deploy their system in Kuala Lumpur. The system mainly works on artificial intelligence and the big data analytics [14].

ASEAN region has the most congestion related problems in Asia-Pacific. Firstly, the transport provided in most of the countries such as Thailand, Vietnam and Philippines is not up to the standard as it should be. The social behavior has contributed significantly in Vietnam's traffic congestion and air pollution 
[15]. The rude driver behavior is also a major cause of traffic congestion and accidents in Cambodia [15]. Unlike European and North American countries, motorcycle is one of the most reliable and cheap way of commuting. Motorcycles are found almost everywhere in ASEAN region and in China. In some cases, the soaring number of motorcyclists does not adhere to the traffic rules and resultantly there is congestion and sometimes accident take place [16]. There are several issues that require timely attention from the authorities; otherwise they can have their adverse aftereffects in the long run.

\subsection{Malaysian Traffic Congestion Scenario}

The dynamics of congestion in Malaysia are not very different than other countries in the nearby region. It is clear that social behavior has contributed to the traffic problems [17]. But there is yet another undeniable fact that is different from other Asian countries and is also overlooked sometimes. Malaysia is the country having third highest private ownership of cars, with most of the people having more than one car [18]. Unarguably this fact can be seen when one is driving there. The other major cause of traffic problem is the weather conditions. Malaysia has one of the highest annual rainfall rates in the world. Sometimes it results in the flash floods. It is often been seen that the flash floods or torrential amount of rain decreases the traffic flow rate substantially [19].

Unlike many cities such as Hong Kong and Singapore, which struggle to find space for more development, Malaysia has ample space to build more roads and highways. Although, the transport facilities provided in Kuala Lumpur are quite adequate but still many people prefer to travel by their own cars. As Malaysia is a diverse and multi-racial country, there are many festivals which are organized by different communities residing in Malaysia. Due to that there is an increase inundation of the people travelling to celebrate the festivals with their loved ones, this result in high levels of traffic congestion even on the highways. Owing to all these problems, the government has taken some steps to deal with them. The city council has made park and ride plazas for those who come distant places. The Park and ride plazas are situated adjacent to the train stations. Many of these facilities are at the outskirts of the city. A park and ride plaza is at Putrajaya Sentral station, which caters to the needs of people going to Kuala Lumpur for work. They park their cars and can easily go for work by using the Putrajaya Electronic Rail Link (ERL) [19].

Since Malaysia is a popular tourist destination. A massive influx of the tourists is experienced by the foreign tourists in Malaysia throughout the year. Many tourists visit the famous sites in Malaysia. As of Kuala Lumpur, due to the tourist activities there is a huge crowd on tourist's attraction, mostly owing to the night life. This is somewhat similar scenario analogous to places in other countries such as, Shinjuku in Japan and Itaewon in Korea. Encapsulating all these situations it is deduced that there are various factors which adds to the misery related with severe traffic congestion. The government and the related departments are concerned and want to suppress these issues for prolong prosperity and for the betterment of the citizens. But there is a need of streamlined and robust roadmap for it.

\section{PLAUSIBLE SOLUTIONS FOR TRAFFIC CONGESTION IN MALAYSIA}

There are numerous avenues which can be addressed to solve the problem of traffic congestion in Malaysia. Various efforts have been done by public and private institutions to mitigate the issue. Local institutions and researchers have given suggestions to use the technology and to induce a gradual reliable mechanism to experience a significant change in the coming future. Some of the possible technological solutions and initiatives have been discussed in the coming sections. The section also recapitulates the endeavors done by the local researchers in this regard.

\subsection{Implementation of Big Data}

In the ASEAN region, the problem of traffic congestion is considered serious. This issue can paralyze the growth of the economy and could create menace for the citizens. The two countries in ASEAN, Malaysia and Singapore, are also facing this problem. The Singaporean government targets a more effective and intelligent transport system for their growing needs. Similarly, Malaysia is also aiming to mitigate the adverse effects being faced by this issue.

There is a huge role big data can play owing to the current scenario of the two major economies of ASEAN region. Recently, Singaporean government has asked their local universities to submit proposals to in order to reduce the transportation commuting time, leveraging the use of big data analytics. This clearly shows the power that BDA can induce to solve the problem. Similarly, the Malaysian authorities are also eyeing to cope up with this issue. There is a large room for the big data to play in Malaysia, as Malaysia has huge transportation infrastructure than Singapore. Taking account of the public transportation, including buses, subways, trains and the highway traffic, it is clearly evident that if the Malaysian government applies BDA for the aforementioned purpose, they will be reaping huge benefits in the future. The big data has been considered 
as a revolutionary factor that will induce a noteworthy change in the coming future. Countries are dealing it with a very proactive approach. The Malaysian government has also given importance to big data revolution. The authorities have taken steps to inculcate the knowledge of big data and are targeting the personnel to get adequate knowledge of it. Big data is deemed very crucial in solving the traffic congestion problem. All the data that government agencies acquire through their sensors or various other sources needs to be processed. In that case, using the power of BDA is one robust way of solving the problem. Besides other issues big data process can be very helpful in solving the congestion.

\subsection{Implementation of MYCityBrain}

There are various opportunities for the technology firms to provide solution for traffic congestion problem. Considering the Malaysian scenario, a key player AliBaBa cloud signed an agreement for providing a platform for Kuala Lumpur in the coming future, which can solve the problem of congestion in the city [14]. The essence of the platform is artificial intelligence and BDA. This really is considered as a breakthrough development as the city has faced a situation of gridlock on many occasions. The platform will be installed in cooperation of city council of Kuala Lumpur and Malaysian Digital Economy Corporation (MDEC). The role of MDEC in increasing the awareness of big data and artificial intelligence is quite commendable. With the advent of the platform in Hangzhou city China, the city has seen remarkable change in congestion.

\subsection{Local Decision Making Framework and a Support for Local Research}

There is a lot of research potential that the traffic congestion can provide to the researchers. The researchers in the local institutes of Malaysia have been very vigilant in solving the real life problem. The public and private higher education institutes have come up with different patents and provided ample research in solving daily life problems of different magnitude. Fortunately the traffic congestion problem has too much to offer to the local researchers, which can be used as a test case for other problems as well. The Singaporean government knows the importance for the home grown research because it flourishes the knowledge and gives numerous opportunities to the researchers. The Singaporean government asked local researchers to come up with a proposal to eradicate traffic congestion. Same approach should be followed in Malaysia. Rather than rendering all the country's talent to others. It is quite intriguing to know that in this scope of research there are a lot of things one can do. To solve the problem using data analytics is only one way of doing it, as shown in Figure 1.

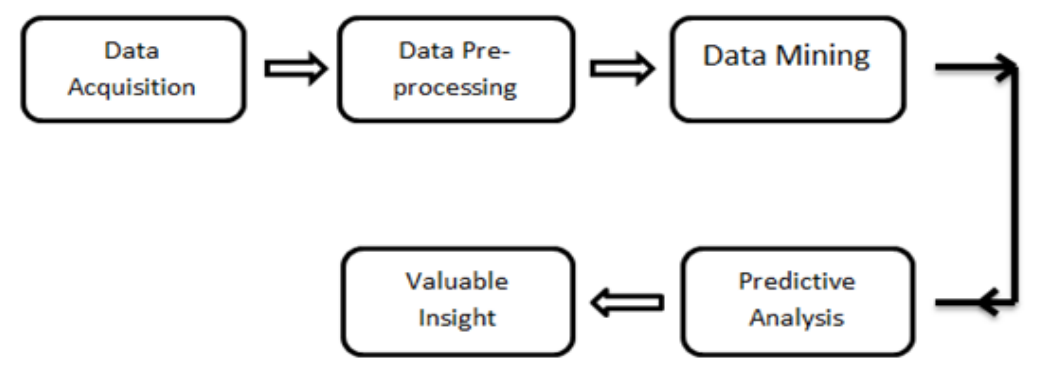

Figure 1. Big data analytics process

The government can acquire the traffic data and can form a data lake for this purpose only, which can be accessed by the local researchers of top institutions. Figure 1, elaborates a simple data analytics process that this paper aims to follow. Firstly the data is acquired. Then the data can be studied and processed. The research worked focused on applying several machine-learning algorithms to train the data so that they can look for a visible pattern and insight as elaborated in Figure 2.

In Figure 2, the predictive analysis from Figure 1 is elaborated a bit more. The machine learning model can be created and then can be tested using the test data. The model will be validated in this manner. In this work three different algorithms are applied to experience an improved accuracy. The applied algorithm can then be improved and can be optimized to give better and accurate results. A framework following this approach can easily be created with minute alterations for solving other problems as well. Some short key components are recapitulated in the Table 1, which are an essential part of the transport framework. 


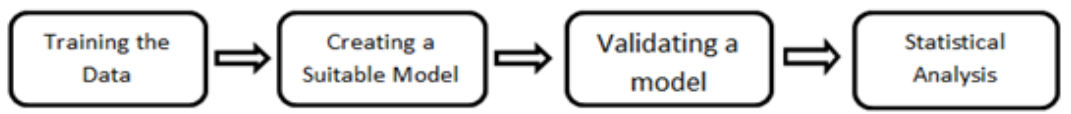

Figure 2. Elaborating the Predictive Analysis

Table 1. A summary of the intended framework

\begin{tabular}{|c|c|}
\hline Acquiring the Data & The Data can be acquired through the sensors, databases, data lakes etc. \\
\hline Data Processing & $\begin{array}{l}\text { Sorting, Summarizing or aggregating the unstructured data. Classifying the } \\
\text { types of data and reporting it. Visualization of the data. }\end{array}$ \\
\hline Creation of the Model & $\begin{array}{l}\text { Using regression analysis, classification, time series analysis, principal } \\
\text { component analysis, artificial intelligence, deep learning and neural networks. }\end{array}$ \\
\hline $\begin{array}{l}\text { Performing the Data } \\
\text { Analysis }\end{array}$ & $\begin{array}{l}\text { Using the tools such as SQL, Hadoop, R or MapReduce to come up with some } \\
\text { valuable insights. }\end{array}$ \\
\hline
\end{tabular}

The approach of the framework is to follow the BDA, which gives the researchers various benefits. Firstly, the Malaysian researcher can get the necessary knowledge about the data science and the other tools such as Hadoop. Secondly, Malaysian institutions will be creating a homegrown talent, which can be very useful for Malaysia's economic prosperity and growth. The future is related to big data and artificial intelligence. The countries are seriously considering investing in these two areas because they see the perks that come along with it. In the same manner the research focuses on implementing a specific transport framework, which uses the power of big data and machine learning, to cope up with the menace of traffic congestion. In this paper, the accuracies obtained by implementing three major machine learning algorithms are mentioned. The machine learning has important place in whole process as it helps us to gain some valuable insights out of the entire system. In this work 200 data samples were taken from Open Traffic platform, an Open source platform provided by Grab. Three machine learning algorithms were been implemented on this set of data to acquire training accuracies of each algorithm. The algorithms work on cross validation, in which we consider seventy percent of the data as training and then thirty percent as test data. For the used set of data of 200 samples, the decision tree algorithm has the highest accuracy, as shown in Table 2, but it can differ greatly as the numbers of data samples are increased. This is what the research work plans to follow in the future that is to look into the possibility and the complete nature of the specific framework that can deal the traffic congestion issue.

Table 2. Training Accuracies for Machine Learning Algorithms

\begin{tabular}{cc}
\hline Technique & Training Accuracy \\
\hline Decision Tree & $94 \%$ \\
Naïve Bayes & $88 \%$ \\
K-Nearest Neighbor & $65 \%$ \\
\hline
\end{tabular}

The result of the intended framework, in which the three machine learning algorithms have been used, can then be utilized in the field of autonomous vehicle (AV), as the AV can make accurate decisions based on the output of the framework, as shown in Figure 3. This feature can help us in getting acquainted with other traits. Some of the areas can be addressed such as the metrics that affects the traffic and induce the congestion. Other benefits include the prediction of traffic behavior, so the authorities can better cope up with the situation. 


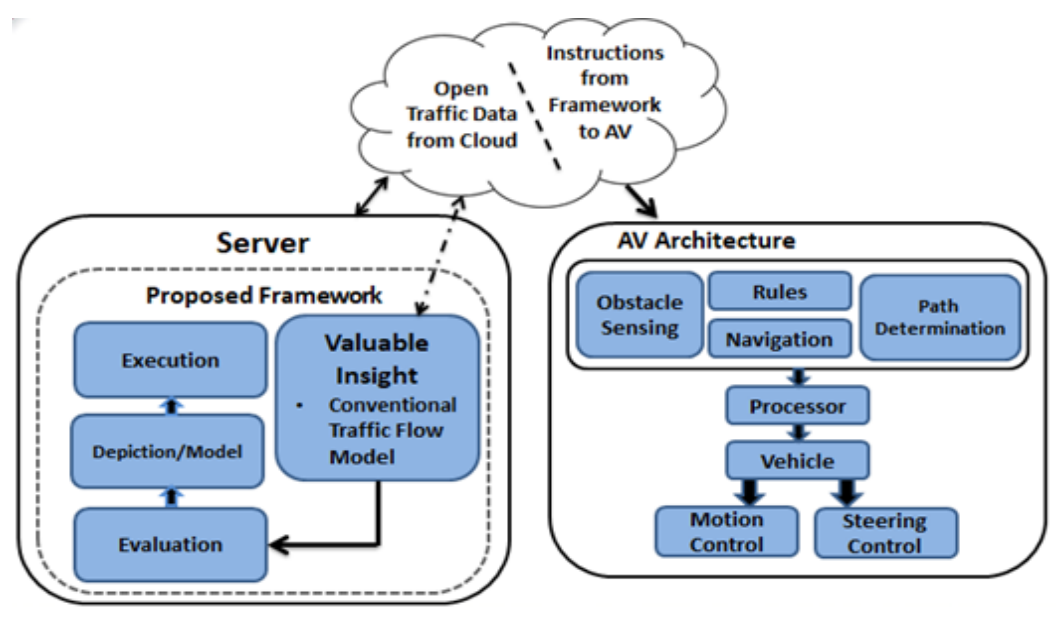

Figure 3. Integration of the Framework to AV Architecture

\section{FUTURE PROSPECTS AND NEED OF A FRAMEWORK}

Malaysia must realize that it has entered into these areas quite readily as compare to many other countries. The potential that the local researcher see must not be wasted and must be utilized by giving opportunities to local researchers and provide them with the platform where they can contribute in the country's growth. MDEC is a sign of Malaysia's readiness, where the corporation has taken initiatives for the prosperous economy. But still there is some vacant space in which the government can provide more facilities to local institutions rather than turning to a foreign source.

The role of big data in eradicating traffic congestion, in Malaysia, is clearly evident. Big data has much more to offer to the country in the coming future. The readiness shown by the government is commendable. The need of the hour calls for availing the opportunity big data has to offer. There are certain challenges, which can be overcome. The challenges should not be considered as a wall; rather the authorities might try to penetrate through it. The benefits that big data process and machine learning has to offer in mitigating traffic congestion will be enjoyed by generations to come.

The authorities need to come up with a standard framework. There is a need of structured framework for transport congestion in sync with big data process. This works target to induce a complete framework in the system. Currently it's at the initial stages. The possible framework can define the country's current standing and a clear cut strategy to define their position on the issue. This framework should be made public and all the major top universities can become part of it. In this way the local researchers can be motivated, be part of the large setup and can contribute with their research findings on big data related with traffic congestion.

\section{REFERENCES}

[1] M. Börjesson, et al., "The Stockholm congestion charges-5 years on. Effects, acceptability and lessons learnt," Transport Policy, vol. 20, pp. 1-12, 2012.

[2] "Low Oil Prices: An Opportunity for Fuel Subsidy Reform." Available: http://energypolicy.columbia.edu/publications/report/low-oil-prices-opportunity-fuel-subsidy-reform.

[3] Jones P. and Hervik A., "Restraining car traffic in European cities: an emerging role for road pricing," Transportation Research Part A: Policy and Practice, vol. 26, pp. 133-45, Mar 1992.

[4] Lim K. K. and Kim S., "An Evaluation of Urban Congestion Charging in Seoul," Journal of the Eastern Asia Society for Transportation Studies, vol. 11, pp. 141-54, 2015.

[5] Goh M., "Congestion management and electronic road pricing in Singapore," Journal of transport geography, vol. 10, pp. 29-38, Mar 2002.

[6] Masjuki H. H., et al., "Potential CO2 reduction by fuel substitution to generate electricity in Malaysia," Energy Conversion and Management, vol. 43, pp. 763-70, Apr 2002.

[7] Nijkamp P. and Kourtit K., "The "new urban Europe": global challenges and local responses in the urban century," European Planning Studies, vol. 21, pp. 291-315, Mar 2013.

[8] Dicken P., "Global shift: Reshaping the global economic map in the 21st century," Sage, Apr 2003.

[9] Bloom D. E., et al., "Population dynamics and economic growth in Asia," Population and development review, vol. 26, pp. 257-90, Jan 2000.

[10] S. Jha, "Oddity of Managing Air Pollution in Delhi: Public Policy Myopia," 2015.

[11] A. M. Willy, "Malaysia to adopt Alibaba's smart city solution," 2018. Available: http://www.theedgemarkets.com/article/malaysia-adopt-alibabas-city-brain-smart-city-solution 
[12] Q. H. Zhang, et al., "The challenge of improving visibility in Beijing," Atmospheric Chemistry and Physics, vol. 10, pp. 7821-7827, 2010.

[13] Mehdi M. R., et al., "Spatio-temporal patterns of road traffic noise pollution in Karachi, Pakistan," Environment international, vol. 37, pp. 97-104, Jan 2011.

[14] C. T. Dung, et al., "Analysis on Characteristics of Passenger Car and Motorcycle Fleets and Their Driving Conditions in Developing Country: A Case Study in Ho Chi Minh City, Vietnam," Journal of the Eastern Asia Society for Transportation Studies, vol. 11, pp. 890-905, 2015.

[15] S. A. Sarm and K. Kanitpong, "Analysis of factors affecting the severity of motorcycle casualties in Phnom Penh using a Bayesian approach," Asian transport studies, vol. 4, pp. 430-443, 2016.

[16] M. Sadullah, et al., "Driving Behavior and Traffic Flow," Asian Transp. Stud., vol. 2, pp. 323-324, 2013.

[17] O. C. Chuen, et al., "Mode choice between private and public transport in Klang Valley, Malaysia," The Scientific World Journal, 2014.

[18] J. Sakamoto and M. Fujita, "Empirical Analysis on the Impact of Rain Intensity on Commuters' Departure Decision on Torrential Rain Day," Journal of the Eastern Asia Society for Transportation Studies, vol. 11, pp. 311-325, 2015.

[19] S. A. A. S. Adnan and A. A. K. Hamsa, "Factors Influencing the Parking Demand of the Park and Ride Facility at Putrajaya Public Transportation Terminal," Journal of the Eastern Asia Society for Transportation Studies, vol. 11, pp. 1291-1306, 2015.

\section{BIOGRAPHIES OF AUTHORS}
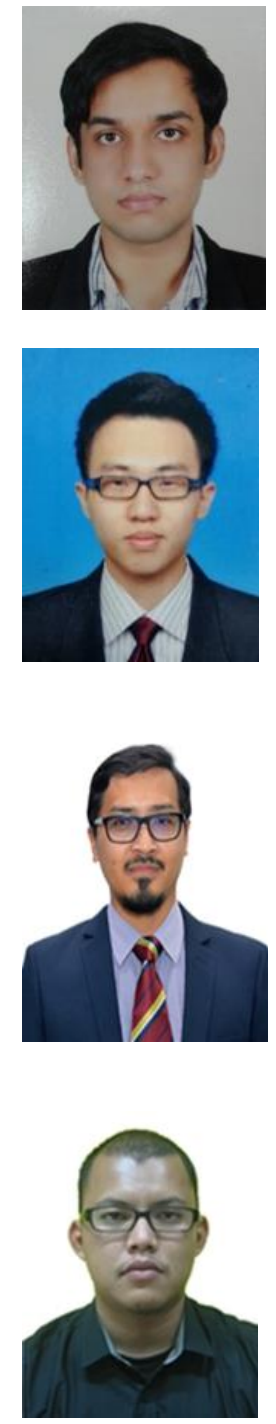

Muhammad Ali completed his Master of engineering (Electronics and Telecommunications) from Universiti Technologi Malaysia in 2016. He received his Bachelors of Science in Electrical Engineering from University of Lahore Pakistan. He is currently doing PhD in department of electrical engineering in Universiti Technologi Malaysia. His topics of interest are big data analytics, machine learning, Internet of Things (IoT), image processing and signal processing.

Tee Kok Sheng is currently pursuing his masters in electrical engineering from Universiti Teknologi Malaysia. He received his B.Eng from Universiti Teknologi Malaysia in 2017. He got the 2nd place as "Best Presenter" award for his final year project in 2017. His research interests include Internet of Things (IoT), Big Data and Vehicular traffic analysis.

Kamaludin Mohamad Yusof received the B.Eng degree in Electrical - Electronics Engineering and M.Eng degree in Electrical Engineering from Universiti Teknologi Malaysia. He received Ph.D degree from University of Essex, U.K. He is currently a senior lecturer in the Department of Communication Engineering, faculty of Electrical Engineering and member of Advanced Telecommunication Technology group at Universiti Teknologi Malaysia. His current research interests include Internet-of-Things, Big Data and Software-Defined Networks.

Muhammad Ramdhan M.S received the B.S. degree in Electrical-Electronic Engineering from Universiti Teknologi Malaysia in 2016 and he is currently enrolled in the M.S. degree in Faculty of Electrical Engineering at Universiti Teknologi Malaysia. His current research interests are in the area of wireless networks including wireless sensor networks (WSN), sports and safety monitoring engineering. 


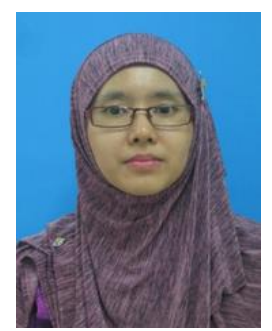

Nurzal Effiyana G received the B.E. (2007) degree from Universiti Teknologi Malaysia. She received two M.E. degree, which is from the Shibaura Institute of Technology (2010) and Universiti Teknologi Malaysia (2011). She received Ph.D. (2016) from Universiti Teknologi Malaysia. Now she is working in Faculty of Electrical Engineering at Universiti Teknologi Malaysia as a senior lecturer who is currently active in research of Mobility Management, Sports Monitoring System, Ubiquitous Network, 5G and Handover Management.

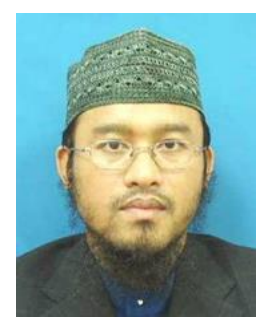

Samura Ali received the Bachelor of Engineering (BE) in Electrical, Electronics and Communications Engineering (1989) from Universiti Teknologi Malaysia. He received a Master's Degree (1998) from the University of Bradford in Electrical, Electronics and Communications Engineering. Currently, now he is working in the Faculty of Electrical Engineering at Universiti Teknologi Malaysia as a senior lecturer. 